\title{
DOMINGO FAUSTINO SARMIENTO: SUS VIAJES, LA MODERNIDAD Y EL APOLOGISMO AL FEDERALISMO NORTEAMERICANO
}

EDUARDO HODGE DUPRÉ

\section{Resumen}

El siguiente trabajo aborda la influencia de Estados Unidos en el pensamiento político del argentino Domingo Faustino Sarmiento. El objetivo es demostrar que sus viajes por aquel país, iniciados en 1847, fueron determinantes en la configuración de sus planteamientos federales. Las apologías de Sarmiento por el modelo norteamericano alcanzaron tales dimensiones, que llegó a sostener que las provincias argentinas alcanzarían la tan anhelada modernidad, si lograban regirse por el mismo sistema.

\section{Palabras clave}

Domingo F. Sarmiento - Federalismo - Historia de las ideas - Argentina siglo XIX - Pensamiento político.

1 Universidad de los Andes, Santiago - Chile.

2 Licenciado en Historia, magíster en Historia, magíster en Estudios Internacionales, doctor en Historia de América y doctor (c) en Relaciones Internacionales. Profesor de la Universidad de los Andes, Chile. E-mail: e.hodge.dupre@gmail.com. 


\section{DOMINGO FAUSTINO SARMIENTO: HIS TRAVELS, MODERNITY AND APOLOGISM TO NORTH AMERICAN FEDERALISM}

The following work analyses the influence of the United States in the political thought of the argentine Domingo Faustino Sarmiento. The objective is to demonstrate that his travel through of that country, begun in 1847, were decisive in the configuration of his federal approaches. Sarmiento's apologies for the North American model reached such dimensions, that he even maintained that the Argentine provinces would achieve the so longed-for modernity, if they were able to abide by the same system.

Domingo F. Sarmiento - Federalism - History of ideas - Argentine Nineteenth century - Political thought. 
Tal como lo exhiben las Cartas Quillotanas ${ }^{3}$, las discrepancias entre Juan Bautista Alberdi (1810-1884) y Domingo Faustino Sarmiento (1811-1888) fueron diversas, constantes y públicas. A mediados del siglo XIX, el tema que los enredaba intelectualmente era la heroicidad del general Justo Urquiza. ${ }^{4}$ Si para Alberdi el vencedor de Caseros debía ser recordado como el "Restaurador", para Sarmiento no era más que un caudillo más de la historia argentina. Pero más allá de estas disputas intelectuales, ambos coincidieron en otros puntos: eran acérrimos opositores al régimen de Rosas; promovían las ideas liberales ${ }^{5}$; veían el desorden político, la anarquía y la inestabilidad institucional como los principales problemas de la nación; y pensaban que era factible organizar las provincias del Plata por medio del sistema federal, similar al implementado por la colonias norteamericanas en 1787.

Sin embargo, en este último punto había dos diferencias que le daban cierta ventaja al sanjuanino sobre el tucumano. En primer lugar, Sarmiento había conocido in situ la operatividad del modelo. Unos pocos años antes de sancionarse la Constitución Argentina de 1853, había recorrido varios Estados de la Unión, observando y estudiando el funcionamiento de sus instituciones. De hecho, en una carta enviada a Manuel Montt el 15 de julio de 1847 desde Paris, declaró que viajaba a Estados Unidos "con el deseo de estudiar la República", aspiración que aparentemente tenía presente desde los tiempos de su juventud (tal como lo señaló en una carta sucesiva). Como se verá más adelante, este periplo fue decisivo para sus planteamientos políticos. Y en segundo lugar, era un franco apologista del federalismo norteamericano, al que conoció, estudió y dispuso todo lo necesario

3 ALBERDI, J.B. Cartas Quillotanas: polémica con Domingo F. Sarmiento, Argentina, 1916.

4 María Cristina SEGHESSO DE LÓPEZ, Sarmiento. Interrogantes y respuestas sobre nuestra República, Argentina, 2012.

5 CRISCENTI, Joseph, Sarmiento and his Argentina, USA, 1993, p. 2.

6 VERGARA, Sergio, Manuel Montt y Domingo Faustino Sarmiento. Epistolario 1833-1888, Santiago, 1999, p. 81. 
para poder aplicarlo cabalmente en las provincias argentinas, pues estaba convencido de que solo así éstas alcanzarían la civilización. ${ }^{7}$

Si Alberdi contribuyó a la discusión sobre la organización política de la nación con sus Bases, Sarmiento hizo lo mismo por medio de dos textos que son sumamente relevantes para comprender sus planteamientos federales. El primero es Argirópolis o la capital de los Estados Confederados del Río de la Plata ${ }^{8}$, de 1850, donde analizó esta forma de gobierno, y sugirió la idea de contar con una capital federal, similar a la norteamericana, en las provincias aledañas al Plata. Y el segundo es Comentarios de la Constitución de la Confederación Argentina", escrito una vez que la obra de Alberdi y la Constitución de 1853 estaban publicadas. Es necesario mencionar los aportes hechos a través de Civilización o barbarie. Vida de Juan Facundo Quiroga, escrita en 1845 y punto de partida de las luces que vendrían después..$^{10}$ Estas obras, sumadas a su prestigio público, lo transforman en un referente obligado para conocer y comprender el pensamiento federal argentino de mediados del siglo XIX.

A pesar de sus escritos, los estudiosos no se han interesado por las reflexiones y apuestas federales de Sarmiento. La mayoría de los eruditos ha empleado el mismo argumento que con Alberdi: como

7 Una de las obras que resalta más esta idea es la biografía elaborada por PALCOS, Alberto, Sarmiento, Argentina, 1962, p. 95. En Comentarios (p. 102), por ejemplo, supuso que la instalación del federalismo, el orden de la república, de la misma forma que lo había hecho Estados Unidos, "darían en pocos años inyectándole la vida y la civilización”. En cambio, autores como Galleti han ironizado al plantear la "exageración" del sanjuanino al momento de pensar el proyecto constitucional argentino como una "mera copia" del norteamericano; vid. GALLETI, Alfredo, en Historia Constitucional Argentina, Argentina, 1974, p. 503. Adriana AMANTE ve otras fuentes de inspiración en estas materias; véase su obra "Sarmiento y sus precursores", en Boletín del Instituto de Historia de Argentina y América Dr. Emilio Ravignani, $\mathrm{N}^{\circ}$ 44, Argentina, 2016.

8 D.F. Sarmiento, Argirópolis o la Capital de los Estados Confederados del Río de la Plata, Argentina, 1850.

9 D.F. Sarmiento, Comentarios de la Constitución de la Confederación Argentina, Chile, 1853.

10 D.F. Sarmiento, Facundo, Venezuela, 1993. 
era contrario a Rosas "el federal”, esto lo convertía ipso facto en "unitario". ${ }^{11}$ Es cierto que el sanjuanino y el tucumano adscribían a esta corriente, pero sólo porque antagonizaban con los autodenominados "federalistas" que despóticamente gobernaban algunas provincias, como Rosas y Quiroga. ${ }^{12}$ Sin embargo, es posible sostener que estos caudillos profesaban un "federalismo" más bien nominal ${ }^{13}$, puesto que en realidad eran "centralistas"; de hecho, sus programas políticos ni se acercaban al federalismo de verdad. Leopoldo Lugones, uno de los principales biógrafos de Sarmiento, señaló refiriéndose a la Generación de 1837: "el éxito de aquélla fue, efectivamente, grande entre la juventud ilustrada de toda la nación, lo cual prueba que llegaba en el momento propicio; y aunque esa juventud era comúnmente unitaria por espíritu de oposición a la tiranía, apreciaba perfectamente las deficiencias de su partido ocasional."

Sarmiento nació el 15 de febrero de 1811 en la provincia de San Juan. ${ }^{15}$ Se desempeñó en distintas ocupaciones, como el periodismo, el

11 En un trabajo relativamente actual, Seghesso de López señaló que las ideas políticas del sanjuanino tuvieron una "divisoria de aguas y juegos de opuestos entre su pertenencia al unitarismo y su adscripción al modelo federal norteamericano desde que visita al país del Norte en 1847 ". Con ello, la autora da a entender que el Sarmiento no se desprendió nunca de su posición unitaria, sin aclarar con mayor fuerza que los unitarios eran más "antirrosistas" que promotores del régimen centralista; vid. SEGHESSO DE LÓPEZ, María Cristina, Sarmiento y el unitarismo argentino, Argentina, 2012, p. 44. Pérez Guilhou incluso aseguró que su federalismo "estuvo bañado de unitarismo"; vid. PÉREZ GUILHOU, Dardo, Sarmiento y la Constitución, Argentina, 1989, p. 72.

12 Un autor que aclara bastante bien esta distinción es SALOMON, Noël, Realidad, ideología y literatura en el Facundo de Domingo Faustino Sarmiento, Holanda, 1984, p. 68.

13 Para una definición más precisa de unitarismo, vid. BAGÚ, Sergio, "Los unitarios. El partido de la unidad nacional”, en Revista de Historia, n² 2, Argentina, 1957; CAMPOBASSI, José Salvador Sarmiento y su época, Argentina, 1975, p. 244.

14 LUGONES, Leopoldo, Op. Cit. p. 127.

15 De acuerdo con una investigación realizada por la U. Nacional de San Juan, la región de Cuyo constituyó uno de los bastiones más importantes del rosismo. De hecho, Mendoza, San Juan y San Luis formaban parte de los "ejércitos combinados" que apoyaban la causa del caudillo. Desde 1852, después de la Batalla de Caseros, que puso fin a la era de Rosas, se inició el proceso de formación del Estado Nacional, que vino a ser confirmado con la Carta Fundamental de 1853. Pero fue después de 1862-año en que comenzó la reunificación 
ejército, la docencia y la política, llegando se ser Senador y Presidente de la República (1868-1874). A la edad de catorce años se radicó en San Luis, acompañando a su tutor que fue exiliado por el gobierno de turno. En 1827 ingresó al ejército federal, pero al poco tiempo se cambió de bando, incorporándose a las tropas unitarias del general Paz. Es probable que en este tránsito haya configurado los primeros esbozos de "civilización" y "barbarie"16, especialmente por las pugnas que mantuvo con Quiroga. ${ }^{17}$ El triunfo federal de 1831 lo obligó a exiliarse en Chile, donde ocupó empleos como la docencia escolar y la minería. Sólo algunos problemas de salud lo llevaron a retornar a Argentina.

De vuelta en San Juan, organizó distintas sociedades. Una de las más importantes fue la Sociedad Literaria (1838), que seguía el ideario de la Asociación de Mayo. ${ }^{18}$ Esto le permitió entrar en contacto con algunos integrantes de la ya señalada Generación de 1837, con quienes compartía el deseo de "completar" lo iniciado en 1810, que consistía en desafectar del poder al general Rosas e iniciar el proceso de renovación cultural e intelectual de las provincias argentinas. ${ }^{19}$ Participó y fundó numerosos periódicos, como El Zonda, órgano que utilizó para generar duros cuestionamientos contra la Mazorca y el régimen por-

de la República- que se hizo efectiva "la plena constitución de los poderes nacionales". A pesar del federalismo contenido en la Constitución, las provincias argentinas afianzaron el "centralismo en detrimento de las provincias", pues las atribuciones provinciales fueron asimilados por el gobierno apostado en Buenos Aires. "Uno de los mecanismos utilizados fue la captación de apoyos entre los sectores dominantes locales y gobiernos provinciales a través de alianzas y coaliciones", política que también afectó a Cuyo.

16 SALOMON, Noel, Op. Cit. p. 18.

17 NOUZEILLES, Gabriela, et. al., The Argentina Reader: History, Culture, Politics, USA, 2002, p. 80 y ss.

18 Fundada con el nombre de "Asociación de la Joven Generación Argentina”, esta institución liberada por Esteban Echeverría nucleó al romanticismo literario nacional y se opuso al régimen rosista. De su seno emergió el Dogma Socialista, cuyas influencias repercutieron muy fuertemente en la vidad intelectual y jurídica de las provincias argentinas; vid. ECHEVERRÍA, Esteban, Dogma socialista, Argentina, 2012, p. 72.

19 LOSADA, Leandro, Historia de las elites en la Argentina. Desde la conquista hasta el surgimiento del peronismo, Argentina, 2012. 
teño. ${ }^{20} \mathrm{~A}$ fines de 1840 fue apresado y luego expulsado de la Confederación. ${ }^{21}$ Nuevamente fijó su residencia en Chile, donde sumó fuerzas para iniciar una campaña internacional contra Rosas. Contribuyó en El Mercurio y El Heraldo Nacional, y fundó El Progreso. También se ligó a temas de educación. Fue nombrado por Manuel Montt para encabezar la Escuela Nacional de Preceptores, cargo que le permitió recorrer Europa, África y Estados Unidos. Maravillado por las instituciones norteamericanas, en 1851 retornó a Argentina, enrolándose en el Ejército Grande ${ }^{22}$ con el grado de teniente coronel.

Sin embargo, diferencias con Urquiza lo obligaron a regresar a Chile. Mientras permanecía en este país, protagonizó una interesante discusión con Alberdi, cuya causa habría sido, según Tulio Halperin, "la paternidad de la etapa de historia que se abre en 1852 ". ${ }^{23}$ Cuando en 1855 volvió a Buenos Aires, ejerció como redactor de El Nacional. Luego de ser Senador durante varios periodos, Mitre lo nombró Ministro de Gobierno, cargo que desempeñó hasta 1862, año en que fue destinado como gobernador de su natal San Juan. En este puesto im-

20 La Mazorca fue el órgano parapolicial empleado por Juan Manuel de Rosas para perseguir a sus enemigos políticos. Estaba compuesta, mayoritariamente, por ciudadanos de Buenos Aires. Pretendía mantener el orden basándose en el empleo ilimitado del terror. Cualquier manifestación que rebajara o que simplemente cuestionara la figura del caudillo, concebido como el “Gran Reformador", era duramente castigada. Se le puede considerar incluso como la fuerza de choque del mismo Rosas y de la Sociedad Popular Restauradora, contra toda manifestación de protesta. Es por eso que seguía tan de cerca los pasos de la Asociación de la Joven Argentina, grupo de intelectuales como Alberdi y Sarmiento, que abogaban por la democracia liberal en desmedro de la tiranía porteña. Se piensa que fue disuelta en 1846. Véase DI MEGLIO, Gabriel, "La Marzorca y el orden rosista", en Prohistoria, vol. 12, Argentina, 2012, pp. 69-90.

21 PALCOS, Alberto, Op. Cit. p. 44.

22 El Ejército Grande fue la unión de fuerzas brasileras, uruguayas, entrerrianas y correntinas, que bajo el mando del general Urquiza, vencieron a Rosas en los montes de Caseros el 3 de febrero de 1852; vid. OBLIGADO, Pastor, La gloria de Caseros: desfile natural del ejército grande aliado en la ciudad de Buenos Aires el 19 de febrero de 1852, Argentina, 1923, p. 5 y ss.

23 HALPERIN D. Tulio., Proyecto y construcción de una nación: Argentina, 1846-1880, Venezuela, 1980, p. 12. 
pulsó importantes mejoras públicas en educación técnica, transporte y comunicaciones. Al poco tiempo fue destinado como diplomático a Chile, Perú y Estados Unidos. Cuando estaba en este último, fue propuesto como candidato presidencial, siendo electo y asumiendo en octubre de 1868. Como máxima magistratura, inició un rápido proceso de modernización en las áreas de educación, ciencia y comunicaciones, todas pensadas para fortalecer el progreso material del país.

Un año después de finalizar su mandato presidencial, asumió como Senador por San Juan. En 1879 aceptó la petición de Avellaneda para ser su Ministro del Interior, pero luego de algunas desavenencias con su estilo político, decidió retirarse del escenario político, al menos por un tiempo. En la administración de Roca también asumió algunas responsabilidades, pero nuevas discrepancias lo hicieron renunciar, echando raíces en el vecino Paraguay, donde murió el 11 de septiembre de 1888 .

Junto con Alberdi y Echeverría, Sarmiento encarnaba los ideales más intensos de la Generación de 1837, cuyo dogma -“de Mayo" como lo denominaba Lugones- se resumía en tres grandes acciones: i) promover "espiritualmente" la democracia; ii) concretarla en la realidad social; y iii) hacer todos los esfuerzos posibles para proyectarla en el tiempo. "Por eso quiso dar a su país las instituciones norteamericanas cuyo ejercicio había visto, atribuyendo (...) la potencia de la Gran República a sus instituciones". ${ }^{24}$ Si bien Lugones no estaba de acuerdo con tildar a Sarmiento como "apologista", lo cierto es que reconoció abiertamente que el sanjuanino explicaba la magnificencia de Estados Unidos a través de su gobierno liberal y federal. Sus viajes, entonces, habrían sido determinantes en su conversión al federalismo. Luego continuó:

Abandona pues, su liberalismo a la francesa, para propagar al americano cuyo

24 LUGONES, Leopoldo, Op. Cit. p. 137. 
otro campeón, Alberdi, continuaba en esto las ideas de Echeverría, también de espíritu políticamente sajón. (...) Lo que verdaderamente representaron fue el espíritu español los federales, y el francés los unitarios, mientras la juventud del Dogma tendió a la democracia angloamericana. ${ }^{25}$

Lugones identificó a Benjamin Franklin como una de las influencias filosóficas más importantes de Sarmiento. Su obra, El Almanaque del Pobre Ricardo, habría sido clave en el fortalecimiento de sus convicciones utilitaristas. Su relevancia fue tal, que Lugones señaló que Franklin era el verdadero "apóstol" que tenía sanjuanino, sobre todo en materias comerciales y económicas. En esta misma línea señaló que "la Vida de Franklin fue su segundo libro revelador; y de aquí provienen seguramente sus inclinaciones angloamericanas, su racionalismo, iniciado por aquellas lecturas protestantes". ${ }^{26}$ En otras obras como Comentarios, son evidentes los aportes Joseph Story, Alexis de Tocqueville y James Madison, como también los otros autores de $E l$ Federalista. ${ }^{27}$ A Story por ejemplo, lo presentó como el principal estudioso y conocedor del régimen norteamericano. Pero además de haber leído a los clásicos, Sarmiento conoció en terreno las instituciones norteamericanas.

25 Ibídem, p. 137.

26 LUGONES, Leopoldo, Op. Cit. p. 159. Otro de los estudiosos que reconoció la influencia de Franklin en la vida Sarmiento fue BRIZUELA, Gabriel, Viajes por Europa, África y América. Su significado en la evolución del pensamiento político de Domingo Faustino Sarmiento, Argentina, 2001, p. 107.

27 En Obras Completas: Provinciano en Buenos Aires: porteño en las provincias, Sarmiento sostuvo la importancia de traducir El Federalista y difundirlo entre las provincias, a través de El Nacional Argentino. Estaba seguro que aquel documento ofrecía todas las soluciones a los problemas que afectaban a su nación, sobre todo aquellos relativos a la organización nacional basada en un gobierno fuerte que a su vez cautelara la coexistencia perfecta entre las distintas esferas de poder. 
Sarmiento habría concebido a Estados Unidos como el paradigma de la modernidad. ${ }^{28}$ Rebeca Errázuriz partió de la base de que los viajes efectuados por algunos pensadores y políticos durante el siglo XIX a través de Europa y América del Norte (a veces voluntariamente, otras producto del exilio) constituyeron no sólo un género literario, sino también una forma de legitimación pública, pues cuando estos regresaban a sus países con ideas nuevas, las defendían apelando a la experiencia in situ. En esta misma línea, Carlos Sanhueza indicó que los intelectuales recorrían las grandes ciudades para lograr una mejor preparación intelectual y política ${ }^{29}$, mientras que Julio Ramos planteó que dichas travesías funcionaron como una práctica habitual de importación de "discursos metropolitanos". ${ }^{30}$ En efecto, estos desplazamientos fueron clave para alcanzar la "experiencia de lo moderno". Sobre lo mismo, Errázuriz señaló:

El viaje latinoamericano en el siglo XIX fue relato del testimonio de una modernidad ejemplar, de la búsqueda de modelos y el reconocimiento de carencias; pero al mismo tiempo fue un acto de independencia, a través de la capacidad de enunciar desde las "tierras bajas" -como diría Sarmiento- un discurso sobre lo moderno. ${ }^{31}$

Pero el viaje también propició la comparación entre lo propio y lo ajeno, "ya sea a través de una proyección utópica que intenta hacerse de un modelo a seguir o de una confrontación con lo extraño, donde

28 ERRÁZURIZ, Rebeca, "Sarmiento y Martí en los EE.UU: imaginarios de la modernidad", en Universum, $\mathrm{N}^{\circ}$ 23, vol. 1, Chile, 2008, pp. 40-65; vid. CLEMENTI, Hebe Sarmiento y su modernidad, Argentina, 1988.

29 SANHUEZA, Carlos, Chilenos en Alemania y alemanes en Chile. Viaje y nación en el siglo XIX, Santiago, 2006, p. 95.

30 RAMOS, Julio, Desencuentros de la modernidad en América Latina. Literatura y política en el siglo XIX, México, 1989, p. 20.

31 ERRÁZURIZ, Rebeca, Op. Cit. p. 2. 
el sujeto corre el riesgo de ser invalidado o devorado por un escenario que sobrepasa los márgenes de su experiencia de mundo." ${ }^{32}$ Esas nuevas realidades eran indudablemente ordenadas, ostentosas y armónicas; no había mitines, persecuciones ni revoluciones; todo era hermoso y moderno. Este encuentro con lo nuevo produjo no sólo un serio contraste con las realidades de origen, sino también un deseo incontenible por replicar en ellas lo recientemente conocido. Según Errázuriz, esto habría provocado en Sarmiento una cierta orientación hacia la "utopía". ${ }^{33}$ Sin embargo, al estudiar las obras del sanjuanino, lo que menos se dilucida es una idea o ilusión sin sustento. Por el contrario, como se verá a continuación, Sarmiento estaba convencido de que era totalmente factible instalar el sistema federal en las provincias argentinas.

Después de dos años recorriendo Europa y África, Sarmiento arribó a Estados Unidos en 1847. Era el momento en que por fin se encontraba con la libertad y el federalismo que solamente había conocido a través de la literatura. Estaba entusiasmado con encontrar allí el modelo de civilización que tanto anhelaba aplicar en las provincias argentinas..$^{34}$ Algunos incluso lo compararon con Tocqueville, que también había cruzado el Atlántico en búsqueda de grandes referencias políticas. ${ }^{35}$ Sarmiento se había desilusionado de Europa; ya no era el ejemplo a seguir. Si bien no presenció los movimientos de 1848, la crisis europea -plasmada en la debilidad institucional, la inclinación hacia el monarquismo y en ciertas contradicciones de clase- hizo

32 ERRÁZURIZ, Rebeca, Op. Cit. p. 2.

33 Eugênio REZENDE DE CARVALHO también sostiene la supuesta mirada utopista de Sarmiento. Véase su obra "La utopía identitaria en Argirópolis de Domingo F. Sarmiento", en Tabula Rasa $\mathrm{N}^{\circ}$ 21, Colombia, 2014, pp. 247-265.

34 IGLESIAS, Hernán, American Sarmiento. Tras los pasos de su viaje que cambió la historia argentina, Argentina, 2013.

35 BOTANA, Natalio, et. al., Vigencia de Sarmiento, Argentina, 1993, p. 13; KRAUZE, Enrique, "Conferencia inaugural. Un puente para las Américas", en FARÍAS, Carolina, El futuro de las Américas. Más allá del libre comercio: los retos del conocimiento, la competitividad y el desarrollo compartido, México, 2004, p. 18. 
que el sanjuanino se inclinara por esa "luz" que él mismo mencionaba en una de las cartas enviadas al viejo Alsina: "Usted y yo, como tantos otros nos hemos envanecido y alentado al divisar en medio de la noche de plomo que pesa sobre la América del Sur, la aureola de luz que se alumbra el norte". ${ }^{36}$

Estados Unidos representaba para Sarmiento lo nuevo, novedoso, desconocido, es decir, "una cosa sin modelo anterior, una especie de disparate que choca a primera vista, y frustra la expectación pugnando contra las ideas recibidas, y no obstante este disparate inconcebible es grande y noble, sublime a veces, regular siempre.” Estas características eran las que según el sanjuanino le daban la estabilidad al país y la fuerza "orgánica” para poder permanecer en el tiempo de forma inalterable. "No es aquel cuerpo social un ser deforme, monstruo de las especies conocidas, sino como un animal nuevo producido por la creación política"37, aunque el argentino tenía algunos reparos que permiten poner en duda la supuesta "utopía” planteada por Errázuriz. ${ }^{38}$ Agregó que, antes de cualquier juicio que se tenga sobre el sistema político norteamericano, era necesario conocerlo apropiadamente, a objeto de dilucidar sus "faltas orgánicas", sus propias condiciones y así no correr el riesgo innecesario de "hallarlo bello, y proclamar un nuevo criterio sobre las cosas humanas", sin una perspectiva crítica. ${ }^{39}$

36 D.F. Sarmiento, Viajes... Op. Cit. p. 290. A propósito de esto mismo, señaló más adelante: "Vengo de recorrer la Europa, de admirar sus monumentos, de postrarme ante su ciencia, asombrado todavía de los prodigios de sus artes; pero he visto sus millones de campesinos, proletarios artesanos viles, degradados, indignos de ser contados entre los hombres; la costra de mugre que cubre sus cuerpos, los harapos y andrajos que visten, no revelan bastante las tinieblas de su espíritu; y en materia de política, de organización social, aquellas tinieblas alcanzan a oscurecer la mente de los sabios, de los banqueros y de los nobles." (Ibíd., p. 334).

37 D.F. Sarmiento, Viajes... Op. Cit. p. 290.

38 Sobre la perspectiva realista y no utópica de Sarmiento, vid. CAMPOBASSI, José S., Sarmiento y su época, Argentina, 1975, p. 265.

39 D.F. Sarmiento, Viajes... Op. Cit. p. 290. 
Una de las primeras cosas que sorprendió a Sarmiento de Estados Unidos fue su geografía. La vastedad y diversidad del territorio lo llevaron a recordar sus provincias argentinas. Pensaba que este factor había sido clave para la "civilización norteamericana", entre otras cosas, porque había facilitado la colonización europea; sus mares, golfos y doble salida marítima dinamizaban su economía; las llanuras permitían una mejor conectividad ferroviaria que, hasta ese momento, era una de las principales expresiones de la modernización ${ }^{40}$; la abundancia y variedad de recursos naturales favorecían la economía interna y externa. Pero a todo esto Sarmiento le añadía otro factor, que había sido el elemento que posibilitó la civilización: "la naturaleza había ejecutado grandes facciones del territorio de la Unión; pero sin la profunda ciencia de la riqueza pública que poseen los norteamericanos, la obra habría quedado incompleta" ${ }^{41}$ Sarmiento creía que todo el éxito se explicaba por medio del "genio de un pueblo", esa capacidad de los ciudadanos para apropiarse de la naturaleza, organizarla y luego ponerla al servicio del progreso.

Otro aspecto que merece atención especial, y que está en estrecha relación con el sistema federal, es la organización política del país por medio de aldeas, entendidas como las primeras piezas de una composición mayor. A diferencia de lo que él había visto en las provincias argentinas (especialmente en San Juan, su tierra natal), "en Estados Unidos la aldea es ya todo el estado, en su gobierno civil, su prensa, sus escuelas, sus bancos, su municipalidad, su censo, su espíritu y su apariencia". ${ }^{42}$ Es interesante también que las aldeas representaban para Sarmiento la igualdad, ese valor que no sólo se reproducía entre los pueblos (o Estados, similares entre sí), sino también entre las personas. Al igual que Tocqueville, el argentino se había sorprendido de que los habitantes no eran distintos entre sí; muy por el contrario,

40 BRIZUELA, Gabriel, Op. Cit. p. 89.

41 D.F. Sarmiento, Viajes... Op. Cit. pp. 296-297.

42 Ibídem, p. 290. 
todos tenían las mismas oportunidades, derechos y deberes..$^{43}$ De esta forma comprendían que antes de pertenecer a la aldea, eran ciudadanos de la República. En esta línea sostuvo:

La igualdad es, pues, absoluta en las costumbres y en las formas. Los grados de civilización o de riqueza no están expresados como entre nosotros por cortes especiales de vestido. No hay chaqueta, ni poncho, sino un vestido común y hasta una rudeza común de modales que mantiene las apariencias de igualdad en la educación. ${ }^{44}$

En este proceso de aprendizaje y asimilación, Sarmiento observó otra cualidad de los norteamericanos que podía servir a los argentinos: "su aptitud para apropiarse, generalizar, vulgarizar, conservar y perfeccionar todos los usos, instrumentos, procederes y auxilios que la más adelantada civilización ha puesto en manos de los hombres". En esto se fundaba lo que denominó como el "carácter único" de los estadounidenses, quienes no tenían la "rutina invencible que demore por siglos la adopción de una mejora conocida; hay por el contrario una disposición a adoptar todo". El sanjuanino intentaba demostrar con esto, que los sistemas políticos de un determinado lugar eran "adaptables" a otro distinto, y que todo dependía de la aceptación popular para aplicarlo o no. Que si los argentinos se lo proponían, era factible implementar el modelo norteamericano en las provincias del

43 Si se sigue la tesis de Verdevoye, Sarmiento contrastó las aldeas francesas con las norteamericanas a objeto de resaltar el modelo norteamericano y desprestigiar el francés, del cual -parafraseando al autor- habló verdadera "peste"; vid. VERDEVOYE, Paul, Domingo Faustino Sarmiento, educar y escribir opinando (1839-1852), Argentina, 1988, p. 411.

44 D.F. Sarmiento, Viajes... Op. Cit. p. 301 . Alberdi también consideró el valor de las unidades menores en el sistema federal. "Si como se dice a menudo, el como vemos en el ejemplo de Estados Unidos de Norteamérica, el poder municipal es el alma del progreso interior del país, y con cuánta mayor razón no se dirá eso del poder provincial, cuya esfera es tan rica y dilatada"; vid. J.B. Alberdi, Organización política y económica de la Confederación Argentina, p. 241. 


\section{Plata, y de paso alcanzar la tan anhelada "civilización". ${ }^{45}$ Sobre este mismo señaló:}

El diccionario de Salvá, porque el de la Academia no hace fe hoy, dice, definiendo la palabra civilización, que es 'aquel grado de cultura que adquieren pueblos y personas, cuando de la rudeza natural pasan al primor, elegancia y dulzura de las voces y costumbres propio de gente culta'. Yo llamaría a esto civilidad; pues las voces muy relamidas, ni las costumbres en extremo muelles, representan la perfección moral y física, ni las fuerzas que el hombre civilizado desarrolla para someter la naturaleza. ${ }^{46}$

Sarmiento asoció la civilización con la "perfección moral y física" del pueblo. Por ello la colonización europea en las provincias argentinas era tan necesaria si se deseaba conseguir esta condición. El desierto era barbarie $e^{47}$, y qué mejor que poblarlo con personas provenientes de lugares más prósperos. El sanjuanino estaba convencido de que la civilización consistía en la capacidad para controlar la naturaleza. Pero cuando el territorio era extenso y diverso como el argentino, la mejor forma para lograr esto era por medio de la federalización, como lo habían hecho los norteamericanos, quienes gobernaban un territorio grande, diverso y de escasa conectividad gracias a la delegación de poder entre las autoridades locales. La clave, según

45 D.F. Sarmiento, Viajes... Op. Cit. p. 301.

46 Idem.

47 En Facundo, el sanjuanino señaló: "el mal que aqueja a la República Argentina es la extensión: el desierto la rodea por todas partes, se le insinúa en las entrañas; la soledad, el despoblado sin una habitación humana, son por lo general los límites incuestionables entre unas y otras provincias. Allí la inmensidad de todas partes; inmensa la llanura, inmensos los bosques, inmensos los ríos, el horizonte siempre incierto, siempre confundiéndose con la tierra entre celajes y vapores tenues que no dejan en la lejana perspectiva señalar el punto en que el mundo acaba y principia el cielo. Al sur y al norte acénchala los salvajes, que aguardan las noches de luna para caer, cual enjambre de hienas, sobre los ganados que pacen en los campos y la indefensas poblaciones (...)”. D.F. Sarmiento, Facundo... Op. Cit. pp. 9 y 10. 
Sarmiento, estaba en la promoción de la igualdad material, porque a pesar de la heterogeneidad, las partes constituyentes eran las mismas ante la ley. No había Estados más o menos adelantados o prósperos, sino unidades simétricas entre $\mathbf{s i}^{48}$. Esto era lo que soñaba Sarmiento para las provincias argentinas, que no eran más que unidades que estaban subsumidas en la violencia y en la dispersión.

En los Estados Unidos la civilización se ejerce sobre una masa tan grande, que la depuración se hace lentamente, reaccionando la influencia de la masa grosera sobre el individuo, y forzándole a adoptar los hábitos de la mayoría, y creando al fin una especie de gusto nacional que se convierte en orgullo y en preocupación. (...) Estoy convencido de que los norte-americanos son el único pueblo culto que existe en la tierra, el último resultado obtenido de la civilización moderna. ${ }^{49}$

El control territorial era uno de los temas que más inquietantes para Sarmiento, pues sabía que ahí estaba el principal fundamento de la civilización. Lo que finalmente había hecho "grande a este este pueblo", era la competencia de los norteamericanos para imponer el orden social y político sobre tan extensas dimensiones territoriales (ese orden visto como un elemento clave en la "prosperidad"50). Alberdi había dado algunas pruebas de esto cuando analizó el caso de California donde las instituciones, la capacidad de diálogo, la asociación y los derechos de propiedad lograron instaurarse rápidamente en un contexto donde no existían más que poblaciones sin el más mínimo ánimo de organizarse. A este ejemplo, se sumaban las experiencias

48 D.F. Sarmiento, Viajes... Op. Cit. p. 313-314. Es cierto que en algún momento señaló que Nueva York era la más rica, y que su Senado debía equipararse al de Roma. Sin embargo, sus niveles de prosperidad en ningún momento eclipsaban al resto de los Estados, como tal vez sí ocurría en las provincias argentinas con respecto al poderío económico de Buenos Aires.

49 D.F. Sarmiento, Viajes... Op. Cit. pp. 313-314.

50 BRIZUELA, Gabriel, Op. Cit. p. 85. 


\section{de todas las demás unidades estatales. Sobre esto mismo Sarmiento señaló:}

El yankee ha nacido irrevocablemente propietario; si nada posee ni poseyó jamás, no dice que es pobre sino que está pobre; (...) y entonces los bosques primitivos se presentan a su imaginación oscuros, solitarios, apartados, y en el centro de ellos, a la orilla de algún rio desconocido, ve su futura mansión, el humo de las chimeneas, los bueyes que vuelven con tardo paso al caer de la tarde el redil, la dicha en fin, la propiedad que le pertenece. Desde entonces no habla ya de otra cosa que de ir a poblar, a ocupar tierras nuevas. Sus vigilias se las pasa sobre la carta geográfica, computando las jornadas, trazándose un camino para la carreta; $y$ en el diario no busca sino el anuncio de venta de terrenos del Estado, o la ciudad nueva que se está construyendo a orillas del lago Superior. ${ }^{51}$

Las grandes ciudades también impresionaron a Sarmiento. Consideraba que las urbes no eran sino la máxima expresión del control territorial alcanzado por los norteamericanos. Eran sinónimo de modernidad y progreso, pero también modelos que los argentinos debían tomar cuando las provincias argentinas comenzaran a crecer en tales dimensiones..$^{52} \mathrm{~A}$ propósito de la ciudad de Búfalo, que le había provocado bastante admiración, quiso destacar sus movimientos portuarios, señalando que "una turba de buques de vapor dejaba escapar de sus chimeneas la gruesa mole de humo del fuego que aún se está encendiendo." Mientras tanto, en el centro de la ciudad, "descu-

51 D.F. Sarmiento, Viajes... Op. Cit. p. 322.

52 HALPERIN propuso un supuesto objetivo de Sarmiento cuando informaba sobre las ciudades norteamericanas: "aunque las ciudades crecían rápidamente, la mayor parte de Europa era predominantemente rural y no podía ofrecer de ningún modo un modelo, ya que sufría las mismas limitaciones, los mismos problemas que él denunciaba y quería superar en la realidad hispanoamericana. Pero cuando llega a París descubre además que el avance de la civilización acentúa constantemente los contrastes y las tensiones. En París encuentra, por una parte, una civilización muy avanzada, un gran refinamiento de costumbres, un lujo deslumbrador que son la contracara de la presencia de un inmenso sector de población miserable que no sólo ofende su sentido de justicia, sino que despierta su alma ante los peligros que encierra. El progreso de Europa es para él, entonces, un progreso hacia nuevos conflictos cada vez más intensos"; vid. HALPERIN D., Tulio, Op. Cit. p. 16. 
bríanse sobre lo alto de los edificios centenares de hombres ocupados afanosamente en construir edificios nuevos, agrandándose la ciudad de improvisto para satisfacer las necesidades de una población que cada año aumenta en veinte mil almas." ${ }^{33}$

Sarmiento dejó Estados Unidos persuadido de que la modernidad no era una entelequia sino una realidad. Allí habían coincidido la prosperidad económica e industrial, la estabilidad política e institucional, la inteligencia para controlar el espacio y explotar los recursos naturales, la promoción de la igualdad social y el resguardo de los valores liberales, insumos necesarios para la construcción de lo que él concebía como "república ideal". El sanjuanino comprendió que dicha modernidad no se había producido de forma espontánea, y que en ello había cobrado un papel decisivo el "genio americano", esa cualidad del pueblo estadounidense para alcanzar la asociación que posteriormente le permitió dominar el vasto territorio y transformarse en la nación poderosa que rápidamente se asomaba en el escenario internacional. En efecto, si Estados Unidos logró estos avances, las provincias argentinas también estaban en condiciones de hacerlo.

Aunque con diferencias, Sarmiento publicó Argirópolis y Comentarios para demostrar la viabilidad de replicar el sistema político norteamericano en las provincias argentinas, a objeto de transformarlas en una nación moderna, próspera y civilizada. En la primera de estas obras, editada en 1850, proponía que la isla Martín García fuera la capital de la Confederación, como Washington lo era en Estados Unidos, autónoma de cualquier provincia. En la segunda, publicada después de que Alberdi difundiera sus Bases y que el Congreso de Santa Fe sancionara la Constitución nacional, intentó emular el trabajo que había hecho Story con la Carta de Filadelfia. ${ }^{54}$ La primera edición es de

53 D.F. Sarmiento, Viajes... Op. Cit. p. 375.

54 Story fue su principal referente al momento de escribir Cometarios. Coinciden en esta idea

GARGARELLA, Roberto, Op. Cit. p. 126; BOTANA, Natalio, "Sarmiento and political order: liberty, power and virtue", en HALPERIN D., Tulio, et. al. Sarmiento: author of a nation, USA, 1994, p. 108. 
septiembre del mismo año, evidenciando la premura que tenía para difundir sus ideas. Entre sus objetivos iniciales, destacan: i) "poner de manifiesto los poquísimos pero capitales errores que inutilizan (...) toda la obra"55; ii) demostrar la factibilidad de replicar el federalismo versión estadounidense en las provincias argentinas por razones de distinta índole (por eventuales similitudes entre los contextos, o por el ya mencionado afán modernizador que movía a Sarmiento):

Sirva esta simple comparación -refiriéndose al federalismo norteamericanopara demostrar lo que nos hemos propuesto en los Comentarios de la Constitución de la Confederación Argentina que principiamos, y es aplicar al texto de sus cláusulas las doctrinas de los estadistas y jurisconsultos norte-americanos, y las decisiones de sus tribunales. ${ }^{56}$

Al redactar los Comentarios, Sarmiento delimitó metódicamente sus marcos constitucionales. Señaló que no era "tanto el texto de las constituciones políticas lo que hace la regla de los poderes públicos", sino más bien los derechos conquistados y las prácticas culturales (o costumbres). ${ }^{57}$ Estados Unidos había dado el ejemplo en ello, mientras que en otras naciones, "la Constitución precede a la posesión de los derechos que asegura, sirviendo sólo de báculo para atravesar, no sin dificultad, por el tango de costumbres y malos hábitos que obstruyen el camino". ${ }^{58}$ Entre estos, Sarmiento resaltaba el faccionalismo político, el caudillismo y la existencia de poderes ilimitados que pululaban por todo el territorio. Planteándolo como una opción correcta, como el modelo a seguir, se refirió al caso norteamericano:

No sucede así empero, con la Constitución federal de los Estados Unidos. En posesión aquellos países de las libertades inglesas, aseguradas por una larga práctica (...) la Constitución era simplemente el prontuario en que se queda-

55 D.F. Sarmiento, Comentarios, Op. Cit. p. 2.

56 Ibídem, p. 4.

57 De acuerdo a Mosquera, en este punto se aprecia la influencia de Montesquieu; vid. MOS-

QUERA, Alberto, Sarmiento y la Constitución nacional, Argentina, 1995, p. 104.

58 D.F. Sarmiento, Comentarios... Op. Cit. p. 2. 
ban consignados los hechos dominantes y los principios que los regían. ${ }^{59}$

Pero Sarmiento advirtió que de nada servía el conocimiento de estas verdades, "si parase sólo en eso". Desde su punto de vista, la Constitución norteamericana había sido legitimada por el tiempo, "pasado por la criba del examen cada una de sus frases, cláusulas y palabras". También tenía la ventaja de haber sido analizada y estudiada por innumerables juristas, historiadores, pensadores en general, y "durante sesenta años los Tribunales federales han dado decisiones judiciales sobre las materias regidas por aquella Constitución”. Según el sanjuanino, la Carta gozaba de tanta "perfección", que los partidos políticos no abordaban cuestiones que no estuviesen contenidas en ella, evidenciando un respeto irrestricto hacia la institucionalidad. ${ }^{60}$ En realidad, "todos los partidos están de acuerdo sobre lo que en el resto del mundo es motivo o pretexto ordinario para las revoluciones y el despotismo". ${ }^{61}$ El objetivo de Sarmiento con toda esta información no era otro que proponer la experiencia norteamericana como la única solución a los problemas argentinos ${ }^{62}$ :

59 Ibídem, p. 3.

60 Entre los argentinos existió la noción de que los norteamericanos eran un ejemplo en cuanto al respeto a las leyes. En El Nacional (Buenos Aires, 8 de octubre de 1852) apareció un artículo que se revela esta admiración: "Los norteamericanos son sin duda en el mundo los hombres que mejor comprenden el deber de respetar las leyes y las autoridades, nacidas entre ellos del sufragio, verdadera expresión de la soberanía del pueblo. Vedlos sin embargo en California, ante el azote de los incendiarios y de los criminales, organizar los ciudadanos jurados populares, usurpar las facultades del Congreso, de la administración y de la magistratura, decretar la muerte y entronizar la bárbara costumbre, llamada entre ellos ley Lynch, porque la ley y el gobierno carecían de acción y de fuerza para escudar a la sociedad en sus peligros".

61 D.F. Sarmiento, Comentarios... Op. Cit. p. 3.

62 Cuestionando de alguna forma las intenciones del sanjuanino, Marta Huertas argumentó: "la tesis que Sarmiento propone en su obra Comentarios de la Constitución consiste en aplicar a la Carta Magna argentina el texto, los comentarios y jurisprudencia de la Constitución norteamericana"; vid. Marta Huertas, El modelo constitucional norteamericano en los fallos de la Corte Suprema de Justicia de la Nación (1863-1903) (Argentina, 2001), p. 37. 
Ahora pues, si nuestro país se constituye bajo el sistema federal, y si adopta en su carta constitucional, hasta la letra de aquella otra Constitución, ya discutida, ya fijada, ya probada, resulta necesariamente que toda la labor de aquella sociedad, que toda su ciencia y experiencia, a la par de la Constitución, a servir de apoyo a la nuestra. La Constitución vendría a ser, pues, para nuestros males, lo que aquellas tisanas, que traen, envolviendo el frasco que las contiene, la instrucción para enseñar la manera de usarlas. ${ }^{63}$

Sarmiento pensaba que todo se simplificaba cuando las Constituciones eran formalizadas. Sólo así quedaban establecidas todas las disposiciones jurídicas que la sociedad esperaba y requería, todo para "que los encargados de ejecutarla no se arroguen atribuciones que no les confiere, ya para que los que han de obedecerla no pretendan, como sucede de ordinario, derechos que ella no asegura". ${ }^{64}$ Quiso distinguir esta idea para dejar en claro que la única finalidad de la ley era limitar el poder. ${ }^{65} \mathrm{Un}$ segundo paso fue ponerla en circulación entre la población, de modo que el común de las personas la conocieran. De hecho, una vez aprobada, lo primero que ordenó Urquiza fue enviar copias del proyecto constitucional a todas las gobernaciones. Sarmiento estaba empecinado en combatir a quienes sostenían que las provincias no estaban preparadas para "instituciones perfectas". No negó que el caos reinante sólo permitía "degollar, robar, haraganear, devastar y destruir", pero abogó incansablemente para que el escenario político fuera ordenado por medio de instituciones rigu-

63 D.F. Sarmiento, Comentarios... Op. Cit. pp. 3-4.

64 Ibídem, p. 4.

65 Sarmiento expuso la trascendencia de los límites del poder y el valor de los deberes y derechos en todo régimen federal: "Una declaración de las garantías y derechos que han asegurado la Unión Norte-Americana la prosperidad que se desea para la Federación Argentina, es un medio de edificar la conciencia pública, mostrándole los instrumentos de ese engrandecimiento, los límites del poder público, y los derechos de los gobernados que no han de atropellarse, so pena de ser sumidos de nuevo en el abismo de males de que acabamos de salir. La declaración de derechos tiene, pues, no solo por objeto poner coto a los desbordes de los poderes públicos, sino educar y edificar la conciencia individual". Íbid., p. 66 . 
rosas. Es aquí donde se hace notoria la figura de Joseph Story, al que Sarmiento llamó como al que "hemos seguido":

Toda duda a este respecto la resuelve el comentario; no el nuestro, a fe, que no hace más que desflorar las cuestiones, sino el comentario norteamericano, que es allí autoridad, y texto para la enseñanza de colegios y universidades; pues la Constitución se enseña y profesa, como toda arte liberal, por pertenecer a esa clase las reglas y prácticas de los grandes principios que responde a algunas de las cualidades nobles de nuestro ser. ${ }^{66}$

Como cada frase contenida en la Carta norteamericana tenía una "importancia íntima”, no estaba permitido "suprimir una frase por parecer innecesaria, desligar un periodo por hallarlo más sonante al oído, etc.”. Al igual que Alberdi, Sarmiento también le dio un carácter científico a dicho código: "si hay fecundidad en esta aplicación de la ciencia y la práctica norteamericana a nuestra constitución, mil trabajos del género pueden emprenderse, y en pocos años enriquecernos con una literatura constitucional, de que carecen por lo general los otros países constituidos." ${ }^{67}$ Esto evidencia que Sarmiento estudió y comprendió el constitucionalismo norteamericano para aplicarlo a la realidad argentina. Pensaba que fortaleciendo las instituciones se podía superar la interminable anarquía, y de paso consolidar la unión. Sin embargo, estaba consciente de que esto no era sencillo, debido a las tensiones que perduraban entre los caudillos. Por eso no es extraño que haya manifestado que "marchamos pues fatalmente a la desmembración". ${ }^{68}$

Todo indica que Sarmiento conocía muy bien las instituciones norteamericanas. ${ }^{69} \mathrm{Al}$ menos así lo demostró cuando señaló que el

66 D.F. Sarmiento, Comentarios... Op. Cit. p. 5.

67 Ibídem.

68 Ibídem, p. 10.

69 En carta a Mitre señaló: "Yo soy federal de convicción. Mis viajes, mi familiaridad con las instituciones norteamericanas me llevan a desear esta forma de gobierno en cuanto sea posible. Nuestras masas populares simpatizan con la palabra, y nuestra tarea debe ser 
preámbulo de la Constitución Argentina había sido tomado de la Constitución norteamericana. Esto no había sido más que el intento "de imponer a la obra nueva de federación sud-americana el sello de la autoridad, (...) y del prestigio de la constitución que le había servido de modelo". Para fortalecer esta idea, el sanjuanino incluso recordó los comentarios de uno de los diputados del Congreso Constituyente, quien habría declarado abiertamente en una de las sesiones, que el preámbulo había sido "una adaptación de aquella Constitución a nuestra federación propia”. ${ }^{70}$

El argentino estaba convencido de que la mejor forma de organizar las provincias argentinas era por medio del sistema federal. A diferencia de otros políticos e intelectuales de la época, tuvo la oportunidad de conocer en persona cómo éste funcionaba en la realidad, permitiéndole superar con creces las suposiciones meramente teórica. Partiendo de la base que "los más fundamentales principios de gobierno están comprometidos en el uso de esta palabra: Confederación”, pensó necesario formular algunas interrogantes que despejaran ciertas dudas sobre lo que realmente significaba esta forma de gobierno. “¿Es una Confederación la República Argentina? ¿Quiere solo indicar la Constitución que lo era tal, hasta el momento de promulgar la Constitución federal? ¿Continúa después de su sanción y adopción, siendo una Confederación? ¿Qué es pues una Confederación?"71 En búsqueda de una definición, indicó:

Una Confederación es, en el sentido genuino, diplomático y jurídico de la palabra en todos los idiomas del mundo, una asociación o liga entre diversos estados, por medio de un pacto o tratado. Las colonias inglesas de Norte América se confederaron entre sí para resistir por las armas a las pretensiones del Parlamento inglés que quería imponerles derechos, no estando ellas representadas en dicho cuerpo. ${ }^{72}$

sólo elevarla de preocupación a institución"; vid. SEGRETI, Carlos, La correspondencia de

Sarmiento, tomo 1, Argentina, 1988, p. 236. (Correspondencia del 10/8/1853).

70 D.F. Sarmiento, Comentarios... Op. Cit. p. 8.

71 Ibídem, p. 11.

72 Ídem. 
Sarmiento sabía que el concepto "confederación" no entrañaba lo mismo que "federación". Que entre ambas había una enorme distancia teórica, práctica e histórica que era necesario tener en cuenta. Señaló que la Confederación organizada por las colonias angloamericanas había cesado desde el momento en que se constituyó un Estado federal, regido por la Constitución de 1788. Justo ahí "la antigua Confederación pasó a ser una Unión de Estados con el nombre de los Estados Unidos de América del Norte". Sugirió comprender la Confederación como "un tratado celebrado entre los Estados o gobiernos" $y$, recurriendo a la obra de Story, concluyó que si bien era un acto soberano del mismo pueblo, no era "de los estados en su capacidad política”. Era más bien una ordenanza o establecimiento de gobierno, y "no un pacto, aunque fuere originado en el común consentimiento". ${ }^{73}$ Tomando nuevamente como modelo la experiencia norteamericana, decidió citar al mismo Story para generar distinciones más claras entre los conceptos:

Su obvio objeto fue sustituir a una confederación de Estados, un gobierno del pueblo, a un convenio, una Constitución. La Constitución fue adoptada para formar una unión más perfecta, que la de la pasada confederación. ¿Bajo qué punto de vista, pues, ha de ser mirada la Constitución de los Estados Unidos? ¿Es un mero pacto, tratado o confederación de Estados, componiendo la Unión? El pueblo ordena y establece una Constitución, no una confederación. La distinción entre una Constitución y una confederación está perfectamente conocida y entendida. La última es mero tratado o liga entre estados independientes, y no obliga sino durante el beneplácito de cada uno. ${ }^{74}$

Al igual que Alberdi, Sarmiento desconfiaba de la confederación como forma de gobierno, simplemente porque ella no había funcionado en Estados Unidos. Sabía que los frutos de la modernización, el progreso, la democracia y la estabilidad institucional apreciados en ese país provenían de la federación, y no de su fase anterior. Demostró la inviabilidad de la confederación por medio de algunos ca-

73 D.F. Sarmiento, Comentarios... Op. Cit. pp. 11-12.

74 İdem. 
lificativos que él mismo denominó como "vicios": desregulación en el plano de las contribuciones, falta de garantías mutas por parte de las unidades miembro, ausencia de un poder directo para levantar ejércitos, igualdad del sufragio para todos los Estados o provincias, carencia de una organización de todos los poderes del gobierno en una sola asamblea, falta de un poder exclusivo en el gobierno federal para emitir papel moneda, votación se hacía frecuente y ausencia de un poder judicial acorde a las circunstancias..$^{75}$

Para el sanjuanino, era fundamental que las diferencias entre federación y confederación fueran conocidas, transmitidas y consideradas. ${ }^{76} \mathrm{~A}$ fin de cuentas, de este pequeño ejercicio dependía el bienestar de la nación y el logro de todos los objetivos que intelectuales y políticos se habían trazado desde San Nicolás de los Arroyos. ${ }^{77}$ En esta misma línea, la visión del sanjuanino pareció ser un tanto pesimista porque, desde la sanción de la Carta de 1853 en adelante, hasta el momento en el que redactó Comentarios, la transición de lo confederal a lo federal no había sido muy efectiva. Más adelante señaló que "la República Argentina continúa siendo una Confederación de Estados o de provincias, aunque esta interpretación conduzca al absurdo y a la negación misma de los objetos y bases de la Constitu-

75 Ibídem. pp. 12-13.

76 SEGHESSO (p. 39) señaló que toda confusión sobre estos términos se debía a las traducciones que se manejaban en aquella época.

77 Después de vencer a Rosas en la Batalla de Caseros, el 3 de febrero de 1852, el General Justo Urquiza convocó a los gobernantes de todas las provincias al poblado de San Nicolás de los Arroyos para comenzar la organización nacional. Tras largas jornadas de trabajo, el 31 de mayo las autoridades firmaron Acuerdo que sería el primer ladrillo de la Constitución de 1853, pues convocaba a un Congreso General Constituyente en la ciudad Santa Fe, a comienzos del año siguiente. Cada provincia debía enviar dos representantes para discutir y sancionar la Carta Fundamental. También se designó a Urquiza como Director Provisorio de la Confederación Argentina, cargo que se sumaba al de encargado de Relaciones Exteriores que había asumido en el mes de abril. Buenos Aires, por su parte, se separó del proceso, grosso modo, porque se le equiparaba a todas las provincias. Véase GARAVAGLIA, Juan Carlos, Construir el estado, inventar la nación: El Rio de la Plata, siglos XVIII-XIX, Argentina, 2007, p. 311. 
ción". ${ }^{78}$ Sarmiento llegó a esta conclusión después de ver el desarrollo de la representatividad en aquel sistema federal, donde el Senado y la cámara baja sólo velaban por los intereses de las provincias, y no por los derechos de los individuos, como debía ocurrir con la cámara de representantes. ${ }^{79}$

Otro de los elementos que podía entorpecer el proceso de organización nacional, y que Sarmiento buscó poner de sobre relieve, fue la confusión que traía consigo el término "confederación": "la palabra Confederación, como designación de la República Argentina, fue introducida en el lenguaje oficial por el Tirano"-refiriéndose a Rosas-, junto a otras palabras "vacías de sentido, o significando lo contrario de la aplicación que él les daba, que entraron en nuestro vocabulario político". Y si bien Sarmiento estaba consciente de que los cuerpos soberanos no lograron legalizar el término, uniformarlo y hacerlo oficial, "aceptáronla y adoptáronla las Legislaturas de las provincias, en la época en que solo eran ecos de la voluntad de los que conjuntamente con el tirano común ejercían el poder discrecional". En efecto, según sus propias palabras, "la República Argentina no fue una confederación, ni podía serlo en realidad." ${ }^{80}$ Por ello le restó poder y relevancia al tratado de 1831:

78 D.F. Sarmiento, Comentarios... OP. Cit. p. 14.

79 Sarmiento estudió la confederación norteamericana a fin de identificar los elementos que la habían llevado al fracaso, y así no replicar este modelo en las provincias argentinas. Por eso le preocupaban tanto los temas de representación, pues sabía que al ser un tema conflictivo en todo proceso de organización federal, podía afectar el proyecto argentino. Sabía que éste había sido uno de los tópicos que hizo tambalear la asamblea de Filadelfia. Como había ocurrido en Estados Unidos, las provincias más grandes podían no ceder ante las más pequeñas e iniciar un conflicto irreversible; Ibídem. p. 17.

80 D.F. Sarmiento, Comentarios... Op. Cit. p. 17. 
Ningún documento público emanado del consentimiento real o asumido de las Provincias Argentinas establece una Confederación; pues el pacto de Santa Fe de 1831 es solo provisorio, y mientras se reúne el Congreso que debe constituir la República bajo la forma federal. ${ }^{81}$

De esta manera, el sanjuanino contradice la versión de algunos historiadores que han visto en el pacto de 1831 el antecedente más inmediato de la Constitución federal de $1853 .{ }^{82}$ No sólo argumentó que dicha alianza ni siquiera tenía el carácter de confederal, sino también responsabilizó a Rosas por haber instalado en la sociedad un término a todas luces erróneo: "debe decirse, al precisar el sentido y mente de la Constitución que analizamos, que la palabra Confederación que aparece en ella es solo una voz legada por la pasada tiranía”, sancionada por el hábito, las costumbres, "impuesta por contemplaciones a consideraciones del momento, y adoptada sin aceptar su importancia política". ${ }^{83}$ Para Sarmiento era muy importante diferenciar ambas formas de gobierno: confederación era sinónimo de inseguridad, fragilidad e inestabilidad, mientras que federación significaba orden y modernización. Más adelante aseguró:

Una confederación reposa en artículos de convenio, mientras que la Constitución crea una forma de gobierno, en la que los poderes, una vez otorgados, son irrevocables, y no se pueden ser resumidos ni retirados cuando se quiere. El uso de la palabra Confederación es simplemente un hábito, que se conserva por la misma razón que se introdujo. ${ }^{84}$

Sarmiento publicó Comentarios a fin de mejorar algunos aspectos que creía frágiles de la Carta de 1853. Este interés se debía a la nece-

81 Ibídem. p. 18. Para una distinción entre ambos conceptos desde una perspectiva historiográfica, vid. CHIARAMONTE José C., Usos políticos de la historia. Lenguaje de clases y revisionismo histórico, Argentina, 2013.

82 Congreso de la República, Primer Congreso del Pensamiento Político Latinoamericano: ponencias y debate, Argentina, 1984, p. 167.

83 D.F. Sarmiento, Comentarios... Op. Cit. p. 18.

84 Ibídem. p. 19. 
sidad de establecer un gobierno fuerte y perdurable en el tiempo. Por eso privilegiaba lo federal sobre lo confederal, porque sabía que este último estaba configurado de una forma que no podía asegurar la estabilidad nacional. Desde su juventud había presenciado lo difícil que había sido la organización política de las provincias argentinas. Ya en la madurez de la vida, lo único que anhelaba era ver a su país ordenado, y encaminado hacia la civilización. Había visto el fracaso de los distintos proyectos constitucionales (desde 1816 hasta 1826), padecido de manera personal los efectos del rosismo y convencido de que las condiciones, en aquel momento, eran las adecuadas para iniciar un proceso de ordenación interna. Sin embargo, seguían existiendo algunos resabios que estaban obstaculizando los avances que él esperaba. Uno de ellos tenía que ver con el lenguaje político predominante:

No podemos vencer nuestra repugnancia contra denominación tan falsa en su acepción natural, como históricamente odiosa. La Confederación es una época de terror y de iniquidades, que debiera quedar aislada y solitaria en nuestra historia, como aquellos monumentos fúnebres que conmemoran calamidades públicas. Pero dar al tirano la gloria de imponerle al país que cubrió de sangre y de crímenes, nombre perdurable, y este nombre ser además la falsificación y un contra sentido. ¿Por qué no llamarnos, como en el Acta de Independencia las Provincias Unidas del Río de la Plata, traducción de los Estados Unidos del Norte de América? Habría habido en ello elevación y propiedad; restablecimiento histórico; y verdad en las palabras. ${ }^{85}$

Esta idea viene a ratificar lo señalado anteriormente: que la palabra "confederación" no sólo era vista como una forma de gobierno insegura, inestable y endeble en el tiempo. Ella también tenía una carga simbólica no menor: era el concepto empleado por Rosas para denominar a su gobierno. Era sinónimo de tiranía, de "terror", de "pasado", de lo mismo que buscaba transformar. Por ese motivo era

85 D.F. Sarmiento, Comentarios... Op. Cit. p. 20. 
fundamental reemplazarlo por "federación", más cercano a la modernidad, al progreso, a la civilización, es decir, a Estados Unidos, república que supo transitar de lo antiguo a lo moderno en el momento preciso. Por ello propuso traducir todo según el patrón norteamericano, visto como el modelo de lo "elevado", de la "verdad", de la libertad. Era el modelo que las provincias argentinas debían seguir si realmente querían alcanzar la democracia, pues instalando sus mismas instituciones facilitaba la superación del tan cuestionado estado colonial. ${ }^{86}$ Pero también era el modelo porque tenían historias similares. Sarmiento señaló al respecto, que los Estados Unidos se hallaban en situación igual en el momento de constituirse", es decir

tenían como la República Argentina inmensos territorios vacíos, y como nosotros el deseo de verlos cuanto antes habitados y convertidos en elementos de poder y de riqueza. El hecho práctico ha mostrado por cuánto ha contribuido al pasmoso y rápido engrandecimiento de aquella nación la latitud dada a la incorporación de nuevos ciudadanos en el Estado, los beneficios de la libertad asegurados a todos los hombres del mundo que quisiesen habitar en su suelo. ${ }^{87}$

En la línea de lo anterior, Sarmiento señaló que "la experiencia de menos de un siglo en los Estados Unidos, la similitud de situación geográfica, de climas templados, y aun de gobierno”, eran causa suficiente para "seguir sus huellas, y aproximárseles no sólo en la forma adoptada de gobierno, lo que sería poco hacer", sino también "en la aplicación de los medios prácticos de acrecentar rápidamente la población y la riqueza", vistas como "dos elementos de la fuerza y la espectabilidad de las naciones, cuando son vivificados por la libertad, que despierta en el hombre la energía moral, intelectual y física". ${ }^{88}$ Sin embargo, a esto era necesario añadirle otra cualidad del ejem-

86 Halperin señaló que Estados Unidos había probado que, siendo una sociedad "marginal, colonial, en su origen bastante pobre", pudo tomar un rumbo propio y alcanzar el éxito material que ya ha sido señalado antes; vid. HALPERIN, Tulio, Alberdi... Op. Cit. p. 18, 87 D.F. Sarmiento, Comentarios... Op. Cit. p. 25.

88 Ibídem, p. 27. 
plo norteamericano, y que Sarmiento consideró como vital para las provincias argentinas: la instauración de políticas que protegieran la propiedad y la vida humana, ambas concebidas como determinantes para alcanzar el bien común, base de toda organización política. En Argirópolis señaló algo similar a esto:

En cuando al mecanismo federal, no hay otra regla que seguir por ahora que la constitución de los Estados Unidos. ¿Queremos ser federales? Seámoslo al menos como lo son los únicos pueblos que tienen esta forma de gobierno. ¿Querríamos acaso inventar otra forma federal desconocida hasta hoy en la tierra? (...) El elemento del orden de un país no es la coerción; son los intereses comprometidos. La despoblación y la falta de industria prohíjan las revueltas: poblad y cread intereses. Haced que el comercio penetre por todas partes. (...) Infundid a los pueblos del Río de la Plata que están destinados a ser una grande nación (...), que un porvenir próximo va a cambiar su suerte actual (...). Llamaos los Estados Unidos de la América del Sud, y el sentimiento de la dignidad humana y una noble emulación conspirarán en no hacer un baldón del nombre a que se asocian las grandes ideas. ${ }^{89}$

Sarmiento no concebía las provincias argentinas bajo otro gobierno que no fuera el federal. Es por eso que se esforzaba tanto en dar a conocer nociones como el bien común y la asociación, factores indispensables para implementar dicho sistema. Pensaba que la dispersión, la incomunicación y los revanchismos entre las provincias estaban socavando la nación. Ello explica en parte la necesidad de "excitar a los pueblos y gobiernos para quienes está calculada esta Constitución, a unirse estrechamente entre sí, y someter sus deseos e intereses a las reglas en ella prescritas". Más adelante indicó: "cada provincia está como una familia en campos solitarios. Si la asaltan malhechores, ¿a dónde acudir por amparo? ¿Quién la oirá, para correr a su auxilio?" 90 Estas preguntas invitan a pensar que Sarmiento también habría comprendido el federalismo como un medio para de-

89 D.F. Sarmiento, Argirópolis... Op. Cit. p. 89.

90 D.F. Sarmiento, Comentarios... Op. Cit. p. 30. 
fender la nación de ataques externos, tal como lo hicieron los autores de El Federalista en su momento.

Sarmiento comprendió el federalismo como un medio para fortalecer el sistema comercial. Sabía que la administración requería rentas para su mantención, y que la mejor forma para lograrlo era fortaleciendo las políticas comerciales. Hasta ese momento, las provincias se habían "consumido y aniquilado en tan largo lapso de tiempo en la ruinosa tentativa de bastarse a sí mismas, y establecer con sus propios elementos toda la maquinaria de un gobierno." ${ }^{.11}$ Cada una de las unidades vivía por su cuenta. No colaboraban entre sí, todo por no tener un eje nacional nítido que las hiciera partícipes de un proyecto mayor. ${ }^{92}$ Tomando como ejemplo el caso norteamericano, Sarmiento señaló que una de las razones más urgentes que había impulsado a las colonias angloamericanas a transitar de un modelo confederal a uno federal, era la mala situación de las colonias: cada Estado estaba "arruinado en sus rentas, como en su comercio, por los otros vecinos, ya que los reglamentos para excluir sus productos, ya con el contrabando para dejar burladas iguales disposiciones". ${ }^{93}$

Y a objeto de prevenir estos mismos problemas en el Río de la Plata, el sanjuanino aconsejó fomentar la confianza y reducir la competencia entre las provincias, pues toda rivalidad entre ellas podía afectar la organización nacional. Sarmiento estaba consciente de que las tensiones causadas por temas comerciales eran inevitables en este momento político. No era fácil renunciar a los intereses provinciales para entregárselos a la Confederación. Ello lo había leído en $E l \mathrm{Fe}$ deralista y comprobado con la escisión porteña. Sin embargo, estaba convencido de que era factible edificar un proyecto que trascendiera

91 Ibídem, p. 31.

92 Más adelante, Sarmiento señaló que la forma federal era el fin de todos los males de las provincias argentinas, pues además de suprimir el alejamiento y promover la ayuda recíproca, lo que más importaba era alcanzar la "común felicidad", cuya incidencia en el proyecto político era fundamental. Ibídem., p. 70.

93 D.F. Sarmiento, Comentarios... Op. Cit. p. 31. 
en el tiempo y diera seguridad a todas las partes integrantes. Para él, "la conciencia de que la unión de los estados es permanente, y no será turbada solo por rivalidades y conflictos de política”, consolidaba el proyecto. En esto, Sarmiento vio la forma para alcanzar el progreso pues, como lo señalaron Hamilton, Madison y Jay, "los caminos serían acortados y mejorados (...), las comodidades para los viajeros multiplicadas y aumentadas (...), una navegación interior por todo el costado oriental (...) mejoras en la navegación fluvial”. ${ }^{44}$ En Argirópolis señaló:

La riqueza de las naciones, y por consecuencia su poder, provienen de la facilidad de sus comunicaciones interiores, de la multitud de puertos en contacto con el comercio de las otras naciones. (...) Los Estados Unidos de Norteamérica son la maravilla de la fácil comunicación de todos los extremos de la unión con el comercio europeo, y de todos los estados centrales con las costas por medio de canales, ríos, ferrocarriles y caminos. (...) Y este prodigioso conjunto de puntos de contactos con el comercio exterior ligado por el más grande sistema de canales artificiales y de caminos de hierro que exista en nación alguna de la tierra. Esta exposición de todos los Estados y este fácil contacto con el comercio exterior (...) hacen de los Estados Unidos, no sólo el Estado más poderoso del mundo, sino que asegura la libertad e independencia de cada Estado de la Unión, respecto a los demás Estados Unidos.95

Y para mitigar las hostilidades interprovinciales y fortalecer la federación, era primordial tener una justicia vigorosa. Sarmiento la consideraba como la "más importante de los ramos del gobierno", pues en ella estaban los cimientos del bienestar, la felicidad humana y la consolidación del proyecto en el tiempo. ${ }^{97}$ Tomando el caso inglés

94 Idem.

95 D.F. Sarmiento, Argirópolis... Op. Cit. p. 128.

96 D.F. Sarmiento, Comentarios... Op. Cit. p. 34.

97 Entre los argentinos reinaba la idea que la felicidad sólo se lograba con la riqueza material. Un ejemplo concreto se puede hallar en el artículo "Historia de los Estados Unidos", publicado por El Nacional (Buenos Aires, 9 de septiembre de 1853). Aquel documento informó que "en estos momentos, en que después de tantos años de atraso e inacción, entramos en una época de reformas, y dirigimos continuamente embelesados nuestra vista hacia la feliz 
como la principal referencia, señaló que la independencia y el buen funcionamiento del poder judicial era el mejor instrumento para salvaguardar la libertad. Sólo así era posible asegurar la normalidad de las leyes y la igualdad entre los hombres. También tiene la virtud de proteger a los ciudadanos de toda opresión, cuestión de suma importancia en una nación que venía saliendo de una tiranía como la de Rosas. En este punto se encuentra el móvil que llevó a Sarmiento a señalar que el mayor fin de la Constitución argentina era afianzar la justicia. En los gobiernos libres, como el angloamericano, la justicia era la base de todas las instituciones. Desde el punto de vista federal, señaló:

Así pues la administración de justicia nacional está destinada a curar las inmundas llagas del aislamiento y de la oscuridad provincial, y establecer un vínculo de unión que ligue a unas provincias entre sí, y a todas con la capital, a prestar amparo a todos los derechos oprimidos en cada localidad y cuyos clamores quedan sofocados por la violencia misma que los arranca. ${ }^{98}$

Pero esa paz que traería la justicia también tenía connotaciones internacionales para el sanjuanino. Sarmiento señaló que si la Carta fundamental lograba "la plácida aurora de la libertad, acompañada de la prosperidad", "nos atraería desde luego las simpatías de la poderosa Unión norteamericana”. Solo así, “cual aliados y socios en la gran causa de la libertad humana”, podían proteger al proyecto de las "complicaciones con la política europea". La Constitución era a fin de cuentas "la fortaleza más inexpugnable que podríamos oponer a los enemigos exteriores". ${ }^{99}$ Sabía que organizando la nación era posible alcanzar el orden interno, cuestión indispensable para generar confianza con los norteamericanos, que se atreverían estrechar lazos comerciales con los argentinos. Sobre esto último señaló

y rica república de la América del Norte, nada nos parece más oportuno que recomendar a nuestra juventud el 'Compendio de la Historia de Estados Unidos'”.

98 D.F. Sarmiento, Comentarios... Op. Cit. p. 44.

99 Ibídem, p. 53. 
El comercio extranjero acumula en los puntos que frecuenta población y riqueza; y la riqueza y población de una ciudad acumulan poder, recursos, inteligencia e influjo, que van más tarde a obrar los otros pueblos colocados en situaciones menos aventajadas..$^{100}$

Sarmiento tenía la convicción de que las provincias argentinas serían modernas en la medida que imitaran la experiencia estadounidense. Y ser modernos implicaba "riqueza y engrandecimiento nacional”, pero en libertad. Pensó que los pueblos que optaban por la tiranía permanecían en la oscuridad, a diferencia de Estados Unidos, donde "asombran los prodigios de engrandecimiento y de riqueza, merced a sus libertades públicas". El sanjuanino pensaba que "la libertad moderna es un capital", que pocas naciones tenían la virtud de poder desarrollarla. En este apartado recurrió nuevamente al juez Story, esta vez para señalar que todo gobierno federal debe preocuparse de los beneficios de la libertad, porque su "gran designio" era precisamente "llenar este importante objeto." Él mismo resumió estas ideas de la siguiente manera:

Y esta es en efecto la forma con que se presenta la República, representativa federal de los Estados Unidos de América, el único modelo de esta forma de gobierno en los tiempos modernos, y por fortuna tan próspero, poderoso y libre, que es de esperar sea el padrón por el cual se guíen todas las asociaciones presentes y futuras, que se hallen en libertad de escoger la forma de gobierno que más convenga a la dignidad de hombres libres y civilizados. Ello es que por un don especial de la Providencia a la República representativa federal, única que representan los tiempos modernos, se asocian indisolublemente las ideas de libertad, riqueza e instrucción individual, engrandecimiento rápido, poder, prosperidad, y tranquilidad imperturbable (...). ${ }^{102}$

Más allá de haber coincidido con Alberdi en la idea de organizar la República Argentina por medio del régimen federal (coincidencia que se suma a la influencia que también ejerció su obra entre los

100 D.F. Sarmiento, Argirópolis... Op. Cit. p. 58.

101 D.F. Sarmiento, Comentarios... Op. Cit. pp. 59-60.

102 Idem. 
constituyentes de 1852, en especial Argirópolis), existe un punto que permite demostrar que Sarmiento tuvo una comprensión más integral del modelo norteamericano que el tucumano (entre otras cosas, porque lo vivió en carne propia). Al menos así quedó establecido en el punto número VIII de Comentarios, donde analizó las relaciones entre el gobierno federal con las provincias, específicamente en el ejercicio de las garantías. Todo el análisis está enfocado en los Artículos 6 y 23 del código fundamental, los cuales regulaban las intervenciones del gobierno central en las provincias y el estado de sitio en casos muy particulares de desorden y perturbación interna. A propósito de que esto debía suceder "al solo objeto de restablecer el orden público perturbado por la sedición”, reconoció que

Esta última atribución del ejecutivo federal está implícita en la constitución de los Estados Unidos, y se comprende en la legislación ordinaria de los Estados particulares, pues es condición necesaria para la felicidad común que el orden constitucional sea mantenido contra la sedición. (...) el aislamiento y separación en que se halla cada provincia requiere que haya más que en parte alguna un poder general que preste su auxilio a las autoridades contra la sedición. ${ }^{103}$

Sarmiento comprendió cabalmente la importancia de instituir un poder Ejecutivo fuerte, tal como en Estados Unidos, cuyo Congreso había fijado "el sentido de esta cláusula en la ley que en 1798 dictó para autorizar al presidente a convocar la milicia para sofocar sediciones en los Estados". ${ }^{104}$ Fue en este punto donde el autor vio que "nuestra Constitución es la misma que la de los Estados Unidos e igual en su aplicación”. ${ }^{105}$ Lo mismo pensó cuando se refirió a las facultades adquiridas por el Congreso argentino para declarar el estado de sitio y en su defecto el Presidente de la República en casos que se produjese una invasión exterior o conmoción interior que pusieran

103D.F. Sarmiento, Comentarios... Op. Cit. p. 195.

104 Ibídem., pp. 195-196.

105 Ibídem., pp. 197-198. 
en peligro el ejercicio de la Carta fundamental y de las autoridades creadas por ella. ${ }^{106}$ Este punto se contrapondría a aquellas posturas que aseguran que el federalismo argentino le otorga menos autonomía a las provincias que el norteamericano. ${ }^{107}$

En consecuencia, de este trabajo se desprenden dos grandes ideas. La primera es la importancia que tuvo para Sarmiento su peregrinaje por Estados Unidos en 1847. Allá pudo maravillarse de la realidad que sólo conocía por medio de la literatura política de la época. Comprobó en terreno que las instituciones políticas funcionaban, que la democracia no era una mera utopía, que la prosperidad material era fundamental para fortalecer los proyectos nacionales, que el valor de la igualdad era posible por medio de códigos que velaran por ella y, lo más importante de todo, que la dominación del espacio y el conocimiento sobre cómo someter la naturaleza eran rasgos esenciales de una civilización. Y la segunda es la visión que tuvo del sistema federal. Es evidente que Sarmiento no era sólo un apologista de esta forma de gobierno. También demostró conocer su teoría y desear replicarlo en Argentina. Para muchos esto era una mera utopía. Sin embargo, todo indica que Sarmiento estaba completamente convencido de que podía transformar a las provincias del Plata en otro Estados Unidos. En una frase que resume su pensamiento, escribió:

106 Esta disposición era la misma que impulsaron los estadounidenses, la cual mandaba a las autoridades a "intervenir sin requisición de las Legislaturas o en su defecto de los gobernadores de estado"; vid. D.F. Sarmiento, Comentarios, p. 203. Al respecto, el sanjuanino señaló que dicho punto era esencial y privativo de las constituciones federales. Aclaró además que los poderes centrales no intervienen en todas las conmociones internas de las unidades miembro, sino sólo en aquellas que pusieran en peligro u obstruyeran el ejercicio de las leyes federales. Por ello era fundamental que se tuviera claridad sobre las facultades de ambas esferas, porque todo lo que afectara a la unidad, debía ser resuelto sus propios dirigentes. Recogiendo la idea de Story, era de vital importancia "repeler los peligros domésticos que pudieran amenazar las constituciones de los Estados"; Ibídem., p. 205

107 GANDULFO DE LA SERNA, Adolfo, La oposición doctrinaria entre Sarmiento y Alberdi, Argentina, 1917, p. 90. 
Los Estados del Plata están llamados, por los vínculos con que la naturaleza los ha estrechado entre sí, a formar una sola nación. Su vecindad al Brasil fuerte de cuatro millones de habitantes, los ponen en una inferioridad de fuerza que sólo el valor y los grandes sacrificios pueden suplir. La dignidad y posición futura de la raza española en el Atlántico, exige que se presente ante las naciones en un cuerpo de nación que un día rivalice en poder y progreso con la raza sajona del norte, ya que el espacio de país que ocupa en el estuario del Plata es tan extenso, rico y favorecido, como el que ocupan los Estados Unidos del Norte. ${ }^{108}$

\section{Bibliografia}

ALBERDI, J.B., Cartas Quillotanas: polémica con Domingo F. Sarmiento, Argentina, 1916.

AMANTE, Adriana, "Sarmiento y sus precursores", en Boletín del Instituto de Historia de Argentina y América Dr. Emilio Ravignani, $\mathrm{N}^{\circ}$ 44, Argentina, 2016.

BAGÚ, Sergio, "Los unitarios. El partido de la unidad nacional", en Revista de Historia, ${ }^{\circ}$ 2, Argentina, 1957.

BOTANA, Natalio et. al., Vigencia de Sarmiento, Argentina, 1993.

BOTANA, Natalio, "Sarmiento and political order: liberty, power and virtue", en Tulio HALPERIN, et. al. Sarmiento: author of a nation, USA, 1994.

BRIZUELA, Gabriel, Viajes por Europa, África y América. Su significado en la evolución del pensamiento político de Domingo Faustino Sarmiento, Argentina, 2001.

CAMPOBASSI, José Salvador, Sarmiento y su época, Argentina, 1975.

CHIARAMONTE, José C., Usos políticos de la historia. Lenguaje de clases y revisionismo histórico, Argentina, 2013.

CLEMENTI, Hebe, Sarmiento y su modernidad, Argentina, 1988.

108 D.F. Sarmiento, Argirópolis... Op. Cit. pp. 88-89. 
Congreso de la República, Primer Congreso del Pensamiento Político Latinoamericano: ponencias y debate, Argentina, 1984.

CRISCENTI, Joseph, Sarmiento and his Argentina, USA, 1993.

DI MEGLIO, Gabriel, "La Mazorca y el orden rosista”, en Prohistoria, vol. 12, Argentina, 2012.

ECHEVERRÍA, Esteban, Dogma socialista, Argentina, 2012.

ERRÁZURIZ, Rebeca, "Sarmiento y Martí en los EE.UU: imaginarios de la modernidad”, en Universum, $\mathrm{N}^{\circ} 23$, vol. 1, Chile, 2008.

FACULTAD DE FILOSOFÍA, HUMANIDADES Y ARTES, U. Nacional de San Juan, Desde San Juan hacia la historia de la región. XVI-XIX, Argentina, 2006.

GALLETI, Alfredo (en Historia Constitucional Argentina, Argentina, 1974.

GANDULFO DE LA SERNA, Adolfo, La oposición doctrinaria entre Sarmiento y Alberdi, Argentina, 1917.

GARAVAGLIA, Juan Carlos, Construir el estado, inventar la nación: El Rio de la Plata, siglos XVIII-XIX, Argentina, 2007.

HALPERIN D. Tulio, Proyecto y construcción de una nación: Argentina, 18461880, Venezuela, 1980.

HUERTAS, Marta, El modelo constitucional norteamericano en los fallos de la Corte Suprema de Justicia de la Nación (1863-1903), Argentina, 2001.

IGLESIAS, Hernán, American Sarmiento. Tras los pasos de su viaje que cambió la historia argentina, Argentina, 2013.

KRAUZE, Enrique, "Conferencia inaugural. Un puente para las Américas", en Carolina Farías, El futuro de las Américas. Más allá del libre comercio: los retos del conocimiento, la competitividad y el desarrollo compartido, México, 2004.

LOSADA, Leandro Historia de las elites en la Argentina. Desde la conquista hasta el surgimiento del peronismo, Argentina, 2012.

MOSQUERA, Alberto, Sarmiento y la Constitución nacional, Argentina, 1995.

NOUZEILLES, Gabriela, et. al., The Argentina Reader: History, Culture, Politics, USA, 2002.

OBLIGADO, Pastor, La gloria de Caseros: desfile natural del ejército grande aliado en la ciudad de Buenos Aires el 19 de febrero de 1852, Argentina, 1923. 
PALCOS, Alberto, Sarmiento, Argentina, 1962.

PÁRAMO DE ISLEÑO, Martha "La dimensión americana del pensamiento de Sarmiento", en Revista de historia americana y argentina, vol. 50, $\mathrm{N}^{\circ} 2$, Argentina, 2015.

PÉREZ GUILHOU, Dardo, Sarmiento y la Constitución, Argentina, 1989.

RAMOS, Julio, Desencuentros de la modernidad en América Latina. Literatura y política en el siglo XIX, México, 1989.

REZENDE DE CARVALHO, Eugênio, "La utopía identitaria en Argirópolis de Domingo F. Sarmiento”, en Tabula Rasa N²1, Colombia, 2014.

SALOMON, Noël, Realidad, ideología y literatura en el Facundo de Domingo Faustino Sarmiento, Holanda, 1984.

SANHUEZA, Carlos, Chilenos en Alemania y alemanes en Chile. Viaje y nación en el siglo XIX, Santiago, 2006.

SARMIENTO, D.F. Argirópolis o la Capital de los Estados Confederados del Río de la Plata, Argentina, 1850.

SARMIENTO, D.F., Comentarios de la Constitución de la Confederación Argentina, Chile, 1853.

SARMIENTO, D.F., Facundo, Venezuela, 1993.

SARMIENTO, D.F. Obras Completas, Capítulo XVI: Provinciano en Buenos Aires: porteño en las provincias, Argentina, 2001.

SEGHESSO DE LÓPEZ, María Cristina, Sarmiento. Interrogantes y respuestas sobre nuestra República, Argentina, 2012.

SEGHESSO DE LÓPEZ, María Cristina, Sarmiento y el unitarismo argentino, Argentina, 2012.

SEGRETI, Carlos, La correspondencia de Sarmiento, tomo 1, Argentina, 1988.

VERGARA QUIROZ, Sergio, Manuel Montt y Domingo Faustino Sarmiento. Epistolario 1833-1888, Santiago, 1999.

VERDEVOYE, Paul, Domingo Faustino Sarmiento, educar y escribir opinando (1839-1852), Argentina, 1988.

Prensa:

El Nacional, Buenos Aires, 8 de octubre de 1852.

Recebido em: 14/12/2017 - Aprovado em: 01/05/2018 